\title{
Methods of competing risks flexible parametric modeling for estimation of the risk of the first disease among HIV infected men
}

Sahar Nouri ${ }^{1}$, Mahmood Mahmoudi ${ }^{1 *}$, Kazem Mohammad ${ }^{1}$, Mohammad Ali Mansournia ${ }^{1}$, Mahdi Yaseri ${ }^{1}$ and Noori Akhtar-Danesh ${ }^{2,3}$

\begin{abstract}
Background: Patients infected with the Human Immunodeficiency Virus (HIV) are susceptible to many diseases. In these patients, the occurrence of one disease alters the chance of contracting another. Under such circumstances, methods for competing risks are required. Recently, competing risks analyses in the scope of flexible parametric models have risen to address this requirement. These lesser-known analyses have considerable advantages over conventional methods.

Methods: Using data from Multi Centre AIDS Cohort Study (MACS), this paper reviews and applies methods of competing risks flexible parametric models to analyze the risk of the first disease (AIDS or non-AIDS) among HIVinfected patients. We compared two alternative subdistribution hazard flexible parametric models (SDH FPM 1 and $\mathrm{SDH}_{\mathrm{FPM}} 2$ ) with the Fine \& Gray model. To make a complete inference, we performed cause-specific hazard flexible parametric models for each event separately as well.

Results: Both $\mathrm{SDH}_{\mathrm{FPM}} 1$ and $\mathrm{SDH}_{\mathrm{FPM}} 2$ provided consistent results regarding the magnitude of coefficients and risk estimations compared with estimations obtained from the Fine \& Gray model, However, competing risks flexible parametric models provided more efficient and smoother estimations for the baseline risks of the first disease. We found that age at HIV diagnosis indirectly affected the risk of AIDS as the first event by increasing the number of patients who experience a non-AIDS disease prior to AIDS among $>40$ years. Other significant covariates had direct effects on the risks of AIDS and non-AIDS.

Discussion: The choice of an appropriate model depends on the research goals and computational challenges. The $\mathrm{SDH}_{\mathrm{FPM}} 1$ models each event separately and requires calculating censoring weights which is time-consuming. In contrast, $\mathrm{SDH}_{\mathrm{FPM}} 2$ models all events simultaneously and is more appropriate for large datasets, however, when the focus is on one particular event SDH FPM 1 is more preferable.
\end{abstract}

Keywords: Competing risks, Flexible parametric models, Multicenter AIDS cohort study, Hazard function, Subdistribution Hazard function, Risk

\footnotetext{
* Correspondence: mahmoodim@tums.ac.ir

${ }^{1}$ Department of Epidemiology and Biostatistics, School of public health,

Tehran University of Medical Sciences, Tehran, Iran

Full list of author information is available at the end of the article
}

(c) The Author(s). 2020 Open Access This article is distributed under the terms of the Creative Commons Attribution 4.0 International License (http://creativecommons.org/licenses/by/4.0/) which permits unrestricted use, distribution, and reproduction in any medium, provided you give appropriate credit to the original author(s) and the source, provide a link to the Creative Commons license, and indicate if changes were made. The Creative Commons Public Domain Dedication waiver (http://creativecommons.org/publicdomain/zero/1.0/) applies to the data made available in this article, unless otherwise stated. 


\section{Background}

There are a variety of possible subsequent outcomes other than Acquired Immunodeficiency Syndrome (AIDS) among HIV-infected patients [1-3]. When our primary focus is on the occurrence of each of these events separately in the presence of each other, the problem of competing risks arises [4, 5]. Competing risks occur when subjects can experience one or more events, which 'compete' with each other and occurrence of one event may prohibit observing the other events or modify their chances of occurrence. With the occurrence of non-AIDS diseases or death prior to AIDS, the true survival time for developing AIDS would be unobservable (e.g., tuberculosis, a lung infection, can expedite progression to AIDS). In general, among HIVinfected patients, diseases can affect each other through immune system suppression. Treatment of one disease may reduce the chance of developing another disease [6-8]. One solution to assess an unbiased estimate of the risk of the event of interest is restricting the analysis to competing events where the follow up for a patient ends at the onset of the first event, and not focusing on multiple events in a patient [9-11]. In this scenario, traditional survival analysis presumes that only one event can occur is not valid and this calls for special methods for competing risks, [5, 12]. Using well-known Kaplan-Meier method, which considers each patient experiencing a competing event as censoring at the time of its occurrence, undermines an important assumption underlying this estimator: independent censoring. However, the subject who was censored due to failing in a competing event will never experience the event of interest as the first event and considering competing events to be independent censorings leads to biases and overestimates the probability of failure $[5,12,13]$. An appropriate measure to evaluate the probability of failure within a competing risk framework is the cumulative incidence function (CIF) [14-16]. It is defined as the probability of failure from the event of interest in an interval of time from the beginning of the study until a particular time when it is quite clear how many subjects experienced competing events.

To evaluate the effects of covariates in a competing risks analysis, model-based approaches on two important measures - the cause-specific hazard and subdistribution hazard- are more common. The difference between these two measures is in their risk sets. In the cause-specific hazard, patients who experienced a competing event will be excluded from the risk set for the event of interest and considered as censored. Modeling on cause-specific hazards provides causal effects of covariates on the hazard of the event of interest in a counterfactual world, where there are no competing events and patients can only fail from the event of interest $[10,11,14,16]$. In contrast, in the cause-specific subdistribution hazard a patient experiencing a competing event will remain in the risk set until the end of the study because he can never experience the event of interest as the initial event. Modeling on subdistribution hazard creates the effect of covariates on the probability of failing in the event of interest at the presence of competing events which is a more realistic depiction of subjects who follow the event of interest and takes into account the chance of failing from other causes prior to the event of interest [5, 16-18]. The choice of modeling hazard or subdistribution hazard depends on the research goals. For etiological goals, to investigate the effect of covariates on the occurrence of a particular event, cause-specific hazard models are suitable. In contrast, for prognosis questions, to know what fraction of subjects at a specified time are at risk of experiencing the event of interest as the first event, considering the fact that they can experience a competing event as the initial event, subdistribution hazard models are preferable $[5,11,12]$. The two most popular models based on cause-specific hazards and subdistribution hazards are Cox and Fine \& Gray regression models respectively $[19,20]$.

There are alternative approaches in modeling of competing risks based on the decomposition of the CIF (i.e., the joint distribution of event times and types of events) known as mixture and vertical models. Mixture models factorize the CIF as the product of the marginal distribution of event type and the conditional distribution of failure time given the type of the event. A multinomial regression model is used to assess the effects of covariates on the type of event and parametric or semi-parametric hazard regression models are used to evaluate their effects on the conditional failure times [21-24]. In contrast, vertical models decompose the joint distribution of event times and types of events as the product of the marginal distribution of time of failure (ignoring the type of event) and conditional distribution of event type given the time of failure, which provides relative hazards [25]. With that said, these models have some difficulties in their estimations, and interpretation of their results and are not practically well-developed [26].

One important issue with Cox or Fine \& Gray models is that the baseline hazard or subdistribution hazard functions remain unspecified and are not estimated parametrically $[4,9,20]$. Their use of partial likelihood functions and inferences are limited to the relative rate of the two hazards or subdistribution hazards. To capture the shape of baseline functions more accurately, the use of parametric models in 
competing risks modeling, and generally for survival analysis, are preferred. The ordinary forms of parametric models (e.g., Weibull and log-logistic have a constraint of linear association between transformations of the survival function and log time [27]. Then the flexibility of the models to fit adequately on the data is limited. So, bias estimations and inaccurate predictions result. In recent years, the application of flexible parametric models in the competing risks modeling for both cause-specific hazard and subdistribution hazard approaches have been proposed [2830]. Flexible parametric models are an extension of parametric models and can be defined on a wide class of different scales (e.g., hazard scale, odds scale or probit). They model a transformation of baseline survival functions on the log time scale using Natural Cubic Splines (NCSs) instead of linear functions and have substantial capabilities in assessing parametric estimates of the absolute measure of hazard or subdistribution hazard of the event of interest at each time point [31, 32].

The primary aim of this paper is to apply two alternative subdistribution hazard flexible parametric models to the HIV-infected men population and compare these models with the Fine \& Gray model as a standard model in competing risks analysis. We have identified the competing risks as the first event - AIDS, non-AIDS, and death prior to AIDS or nonAIDS diseases - in an HIV-infected male population and evaluated the covariates that are associated with the risks of these outcomes. Furthermore, we implemented a cause-specific hazard flexible parametric model to investigate the direct (causal) and indirect (noncausal) effects of covariates on the risk of the competing events. In the next section, we present a description of the Multicenter AIDS Cohort Study (MACS). In the third section, the association of the cumulative incidence function with the hazard and subhazard functions is explained. In the fourth section, the Competing risks flexible parametric models $\left(\mathrm{CR}_{\mathrm{FPM}} \mathrm{s}\right)$ for multiple types of events are reviewed. In the fifth section, the $\mathrm{CR}_{\mathrm{FPM}} \mathrm{S}$ are applied to the MACS dataset and predictions for the risks are obtained. The last two sections contain results and conclusions.

\section{Study description}

\section{Study population and patient selection}

Multi Centre AIDS Cohort Study (MACS) is a 30year prospective study of HIV infection among homosexual or bisexual men (HBM) who were 18 years or older with no prior AIDS-defining illness. MACS began in 1984 at four US sites; Chicago, Illinois; Baltimore, Maryland; Pittsburgh, Pennsylvania; and Los Angeles, California. It has multiple patient recruitments. The first recruitment, which consists of 4954 HIV-infected and uninfected HBM was conducted in 1984-1985. In 1987-1990, recruitment was reopened and $668 \mathrm{HBM}$ were enrolled. During 20012003 another 1350 HBM were enrolled. Another MACS expansion commenced at the beginning of 2010 and 371 HBM were recruited until April 2014. HIV-related symptoms, demographic characteristics, blood specimens, and behavioral history at each 6month follow-up visit were collected. Among 7232 HBM, seroconverter patients were selected and patients with a non-AIDS disease before seroconversion were excluded from the study. This analysis includes 674 seroconverter or prevalent patients with a known visit of seroconversion.

\section{Outcomes and covariates}

Study outcomes were determined as the time duration from seroconversion to the occurrence of the first event. The midpoint of the last negative and the first positive visits was used as the time of seroconversion. The primary event was the occurrence of AIDS without evidence of a non-AIDS disease before. The secondary event was time to a non-AIDS disease prior to AIDS. Non-AIDSs included the following diseases: kidney, liver, cardiovascular, cerebrovascular diseases; lung infection, bacteremia, septicemia; malignancies, neurologic; cancers -all cancers excluding Kaposi sarcoma, lymphoma, and invasive cervical cancer. Since the occurrence of death precludes observing AIDS or non-AIDS diseases, we considered unrelated death as the third outcome. These types of deaths may occur for reasons unrelated to AIDS or nonAIDS diseases (e.g., cerebral artery occlusion). Other patients who were lost to follow-up or did not experience any failure event at the end of the study (i.e., April 2014) were censored. Such variables as MACS recruitment calendar years, age at seroconversion time, laboratory results including the number of positive CD4 cell counts, CD8 cell counts, white blood cells, red blood cells and platelets at baseline were considered based on the expert knowledge and previous studies on HIV/AIDS [6, 7, 33, 34]. Measurements obtained at the first positive visit are referred to as 'baseline'. We used categorical covariates instead of continuous to have perceptible clinical interpretations. The cut points were determined based on clinical considerations and previous studies on the MACS data [33-38]. Sparse groups were integrated with adjacent categories. The study follow-up time was restricted to 15 years from HIV positive diagnosis to exclude non-AIDS diseases or causes not related to HIV infection or death related to aging. 


\section{Relations of risk with Hazard and subhazard functions}

Cause-specific CIF is a measure of absolute risk and defined as the probability of failure from $\mathrm{k}^{\text {th }}(\mathrm{k}=1 \ldots \mathrm{K})$ cause by time $t$ while being at risk of failing from other competing events [9]. So, we have:

$$
F_{k}(t)=p(T \leq t, \text { event }=k)=\int_{0}^{t} h_{k}^{c s}(u) \cdot S(u) d u
$$

In the above equation, $F_{k}(t)$ is the CIF function, $T$ is the survival time i.e. the minimum of the true survival time and censoring time, $h_{k}^{c s}(u)$ is the cause-specific hazard functions at time $u \leq t$. $S$ is the overall survival function and is defined as.

$$
\checkmark(u)=\exp \left\{-\sum_{k=1}^{K} \int_{0}^{u} h_{k}^{c s}(v) d v\right\} .
$$

Equation (1) implies that the risk of the event of interest is the combination of its hazard $\left(h_{k}^{c s}\right)$ and the chance that competing events get to the event of interest to occur as the first event $(S)$. An increase in the hazard of competing events will lower the risk occurrence of the event of interest as the first event by decreasing the overall survival function. In other words, in a competing risks framework, a covariate can increase the risk of the event of interest directly via increasing the hazard of the event or indirectly by decreasing the hazards of competing events. So, a discrepancy between the hazard and risk of the event of interest may be observed. The magnitude of this discrepancy depends on the severity of competing risks. The stronger the competing risk, the greater the discrepancy $[10,12,14]$. The cause-specific hazard is the instantaneous failure rate from a particular event among patients who did not experience any prior competing events and has the form of

$$
h_{k}^{c s}(t)=\operatorname{Lim}_{\Delta t \rightarrow 0}\left\{\frac{p(t \leq T<t+\Delta t, \text { event }=k \mid T \geq t)}{\Delta t}\right\} .
$$

In contrast, the cause-specific subdistribution hazard is defined as

$$
h_{k}^{s d}(t)=\operatorname{Lim}_{\Delta t \rightarrow 0}\left\{\frac{p(t<T \leq t+\Delta t, \text { event }=k \mid T>t \cup(T<t \cap K \neq k))}{\Delta t}\right\} .
$$

Although this definition of the risk set is not practically meaningful because the patient does not actually remain in the risk set to experience the event of interest as the first event; however, this can lead to the following direct relationship between subdistribution hazard functions and corresponding cause-specific CIFs:

$$
F_{k}(t)=1-\exp \left\{-\int_{0}^{t} h_{k}^{s d}(u) d u\right\}
$$

So, modeling on cause-specific subdistribution hazard will show the associations between covariates on the cause-specific CIF. The subdistribution hazard-based models use the information that the occurrence of competing events gives about the event of interest. That is, the event of interest never occurs as the first event if a competing event has already occurred. So, whenever a competing event occurs the chance of occurrence of the event of interest as the first event will be reduced. However, to investigate whether an association is direct or indirect the effect of the covariate on all cause-specific hazards should be assessed.

\section{Models}

Cause-specific Hazard flexible parametric models

The $\mathrm{CSH}_{\mathrm{FPM}}$ performs a flexible parametric model for each type of event separately considering competing events as censoring. It regresses the cause-specific log cumulative hazard function on a Natural Cubic Splines (NCSs) function of the log of time that is

$$
\begin{aligned}
\ln H_{k}^{c s}\left(t \mid X_{k}\right) & =\ln H_{0 k}(t)+X_{k} \beta_{k} \\
& =N C S_{k}\left\{\ln t ; \gamma_{k}, d_{0 k}\right\}+X_{k} \beta_{k}
\end{aligned}
$$

Where $H^{c s}(t \mid X)$ is the cause-specific cumulative hazard function for event k with matrix $X_{k}$ of covariates at time $t, H_{0 k}(t)$ is the cause-specific baseline cumulative hazard function, $\beta_{k}$ is a vector of covariates coefficients and $N C S_{k}\left\{\ln t ; \gamma_{k}, d_{0 k}\right\}$ is a natural cubic spline function of $\ln (t)$ with $d_{0}$ knots and parameters $\gamma$ for event $\mathrm{k}$. The number and position of knots in the spline function determine the complexity of the baseline cumulative hazard function. However, sensitivity analysis showed that they have little effect on the model fitting and there is no need for optimal selection to have a good fit [31]. Model [3] has the capability of carrying time dependent effects of covariates, for handling nonproportional hazards (non-PH) form, easily through incorporating the interactions of covariates with spline functions [32].

Instead of separate $\mathrm{CSH}_{\mathrm{FPM}} \mathrm{S}$, Hinchliffe and Lambert introduced a unified $\mathrm{CSH}_{\mathrm{FPM}}$ on stacked data based on the Lunn-McNeil approach [28, 39]. In the stacked data, each patient has one row of observations for each particular competing event to have the opportunity of failing in that event. For each event type, an indicator variable would be added to the data. An additional indicator variable also would be 
created to identify the type of event for each patient. The unified $\mathrm{CSH}_{\mathrm{FPM}}$ is fitted for all competing events simultaneously and parameters related to each competing event are jointly estimated [40]. Different baseline hazard functions are considered for each cause of failure. This approach has the capability of considering shared covariate effects for all competing events. If knot positions in the unified model are the same as those in separate $\mathrm{CSH}_{\mathrm{FPM}} \mathrm{S}$, covariate estimations of this model would be equivalent to those obtained from separate models [40, 41].

\section{Subdistribution Hazard flexible parametric models (SDH FPM $_{\text {) }}$}

In the $\mathrm{SDH}_{\mathrm{FPM}}$, the effects of covariates directly model on the cause-specific log cumulative subdistribution hazard functions using NCSs as follows:

$$
\begin{aligned}
\ln H_{k}^{s d}\left(t \mid X_{k}\right) & =\ln \left(-\ln \left(1-F_{k}\left(t \mid X_{k}\right)\right)\right) \\
& =N C S_{k}\left\{\ln t ; \gamma_{k}, d_{0 k}\right\}+X_{k} \beta_{k}
\end{aligned}
$$

Lambert et al. proposed a parametric version of the Fine \& Gray model [29]. Patients who experienced a competing event are kept in the risk set and have the chance of being censored before the end of the followup. The survival time is defined as the minimum of censoring time and true survival time. So, the censoring probabilities should be calculated and incorporate in the likelihood function for obtaining an unbiased estimation of the subdistribution hazard for the event of interest [40]. Fine and Gray calculated the censoring probabilities non-parametrically and used inverse probabilities of censoring weights in the partial likelihood function [20]. In the Lambert model, the censoring distribution is estimated parametrically using FPMs. They used a weighted likelihood where weights are conditional probability of not being censored after experiencing a competing event which is time dependent because the censoring probability grows over time. In addition, they extended the Geskus approach to be able to estimate $\mathrm{SHD}_{\mathrm{FPM}}$ using standard software of FPMs [42]. To achieve this, the follow up time after competing event would be split into a number of intervals and time dependent weights are applied to each interval. Then, standard packages for FPMs can be applied for the event of interest [29]. Lambert showed that there is no need to have a very fine number of splits and the bias of estimation is negligible. Like the Fine \& Gray model, the Lambert model is fitted for each event of interest separately $[29,41]$.

As an alternative method, Mozumder et al. introduced a unified likelihood function to obtain a direct estimate of all cause-specific CIFs simultaneously using FPMs [30]. This model is also on the log cumulative subdistribution hazards scale (Eq. (4)). In this method, however, instead of using the censoring weights, the likelihood function is directly constructed based on subdistribution hazards and CIFs $[30,43]$. We hereafter refer to the former subdistribution hazard model as $\mathrm{SDH}_{\mathrm{FPM}} 1$ and the latter as $\mathrm{SDH}_{\mathrm{FPM}} 2$.

\section{Statistical analysis}

We performed a Complete Case Analysis (CCA), 629 of 674 patients, and assumed the data were Missed Completely at Random (MCAR). However, Multiple Imputations (MI) using the multivariate normal regression method with 10 imputed data sets for missing data were performed to explore the sensitivity of the inferences to departures from MCAR assumptions.

The possibility of a reduction in the number of initial set of covariates, generated based on the expert (background) knowledge, was explored. We used transcan function in $\mathrm{R}$, which transforms covariates while imputing missing values of them [44]. The transformation for each covariate is conducted using canonical variates in a way that the covariate has the maximum correlation with the optimum linear combinations of other covariates. The number of knots for baseline hazard and subhazard functions were determined using the Akaike Information Criterion (AIC) statistic. We used main effects of covariates and started with five degrees of freedom and identified the complexity of models based on the lowest value of AIC. Internal and boundary Knots for NCSs of each competing event separately located in their equally spaced centiles and the first and last event times respectively. After determining the optimal number of knots for each model, a forward stepwise regression method was performed to build final models [45]. However, we did not consider variable selection on CD4 cell count due to its important role in HIV/AIDS studies. In $\mathrm{SDH}_{\mathrm{FPM}} 1$, for patients experiencing a competing event the time was split every .1-year. The time dependent censoring weights were estimated through fitting an FPM on the initial set of covariates, with three degrees of freedom. The $\mathrm{CSH}_{\mathrm{FPM}} \mathrm{S}$ were conducted for each event separately.

All significant effects were detected using the Likelihood Ratio (LR) tests at a 5\% level. The findings are summarized with hazard and subdistribution hazard ratios and 95\% Confidence Intervals (CI). Statistical analyses were performed in STATA (StataCorp. 2017. Stata Statistical Software: Release 15. College 
Table 1 Baseline Characteristics of Seroconverter HBM in the MACS Data

\begin{tabular}{|c|c|c|c|c|}
\hline Variables & *patients & $\begin{array}{l}\text { AIDS } \\
(N=267)\end{array}$ & $\begin{array}{l}\text { Non-AIDS } \\
(N=156)\end{array}$ & $\begin{array}{l}\text { Death } \\
(N=25)\end{array}$ \\
\hline MACS recruitment & $N=674$ & & & \\
\hline $1984-85$ \& 1987-90 & $581(86.20)$ & 266(99.63) & $132(84.62)$ & 23(92.00) \\
\hline $2001-3 \& 2010$ & $93(13.80)$ & $1(0.37)$ & 24(15.38) & $2(8.00)$ \\
\hline Age at diagnosis & $N=667$ & & & \\
\hline$<40$ & 473(70.91) & 205(77.36) & $94(60.26)$ & 14(58.33) \\
\hline$\geq 40$ & 194(29.09) & $60(22.64)$ & $62(39.74)$ & 10(41.67) \\
\hline Baseline CD4, per $\mu \mathrm{l}$ & $N=629$ & & & \\
\hline$<350$ & $51(8.11)$ & $22(8.84)$ & $9(6.04)$ & $0(0.00)$ \\
\hline $350-500$ & 102(16.22) & $47(18.88)$ & 16(10.74) & 6(31.58) \\
\hline$\geq 500$ & $476(75.68)$ & 180(72.29) & 124(83.22) & 13(68.42) \\
\hline Baseline CD8, per $\mu \mathrm{l}$ & $N=629$ & & & \\
\hline$<500$ & $91(14.47)$ & $45(18.07)$ & $17(11.41)$ & $4(21.05)$ \\
\hline $500-1000$ & $337(53.58)$ & $129(51.81)$ & 79(53.02) & 12(63.16) \\
\hline$\geq 1000$ & 201(31.96) & 75(30.12) & $53(35.57)$ & $3(15.79)$ \\
\hline Baseline WBC, per $\mu \mathrm{l}$ & $N=663$ & & & \\
\hline$<5000$ & 191(28.81) & 78(29.43) & $39(25.32)$ & $10(43.48)$ \\
\hline$\geq 5000$ & $472(71.19)$ & $187(70.57)$ & $115(74.68)$ & $13(56.52)$ \\
\hline Baseline $\mathrm{RBC}, \times 10^{5}$, per $\mu \mathrm{l}$ & $N=667$ & & & \\
\hline$<4.5$ & $90(13.49)$ & 25(9.43) & $31(19.87)$ & $1(4.17)$ \\
\hline$\geq 4.5$ & $577(86.51)$ & $240(90.57)$ & 125(80.13) & 23(95.83) \\
\hline Baseline platelets, $\times 10^{3}$, per $\mu \mathrm{l}$ & $N=660$ & & & \\
\hline$<150$ & $40(6.06)$ & 10(3.77) & $9(5.92)$ & 6(26.09) \\
\hline $150-250$ & $347(52.58)$ & $127(47.92)$ & $90(59.21)$ & 8(34.78) \\
\hline$\geq 250$ & 273(41.36) & $128(48.30)$ & $53(34.87)$ & $9(39.13)$ \\
\hline
\end{tabular}

*Differences between the number of patients and the sum of the AIDS, Non-AIDS and Death columns indicate the number of censored patients

Station, TX: StataCorp LLC.) and R (Version 3.5.2) [46].

\section{Results}

The descriptive statistics for patients in the study are reported in Table 1. Patients who were diagnosed with AIDS as the first event tended to be younger, have more prevalence in 1984-85 and 1987-90 recruitments, lower $\mathrm{CD} 4$, higher $\mathrm{CD} 8$, and higher $\mathrm{RBC}$ in comparison with patients who were diagnosed with non-AIDS diseases as the first event. The results of transcan function showed that none of the covariates selected by the expert (background) knowledge had strong correlations with the others (refer to Additional file 1: Table S1). The AICs and BICs in all three $\mathrm{CSH}_{\mathrm{FPM}}, \mathrm{SDH}_{\mathrm{FPM}} 1$ and $\mathrm{SDH}_{\mathrm{FPM}} 2$ with $3,1,1$ knot(s) for AIDS, nonAIDS, and death respectively, had minimum values. For all $\mathrm{CR}_{\mathrm{FPM}} \mathrm{S}$, Interactions between the age with $\ln (\mathrm{t})$ on non-AIDS diseases was statistically significant $(\mathrm{LR}$ test $P$-values $=.05, .021$ and .024 , for
CSHFPM, SDHFPM1 and SDHFPM2, respectively). More complicated time dependent effects of age had been assessed. However, $\ln (\mathrm{t})$ had the lowest AIC and BIC among them. Table 2 presents the results of multivariable $\mathrm{SDH}_{\mathrm{FPM}} 1, \mathrm{SDH}_{\mathrm{FPM}} 2$, and Fine \& Gray model, which show the effects of covariates on the subdistribution hazards or equivalently on the risk of the first observed event. There was a high agreement between estimated subhazard ratios obtained from Fine \& Gray and two $\mathrm{SDH}_{\mathrm{FPM}} \mathrm{s}$. The results of performing $\mathrm{CSH}_{\mathrm{FPM}}$ also show the effects of covariates on the hazard of each event separately (refer to Table 2). For simplicity, we refer to 1984-85 and 1987-90 MACS recruitments as period 1 and 2001-3 and 2010 recruitments as period 2. The rest of this section is concentrated on the results of $\mathrm{SDH}_{\mathrm{FPM}} 1$ and $\mathrm{CSH}_{\mathrm{FPM}}$. However, due to the fair agreement between models, the $\mathrm{SDH}_{\mathrm{FPM}} 2$ would have the same interpretation. The interpretation of subdistribution hazard ratios is not often appealing. It should be noted that their magnitudes are not 
Table 2 Cause-Specific and Subdistribution Hazard Ratios Estimated from the Cause-Specific Hazard (CSH FPM) and Cause-Specific Subdistribution Hazard models (SDH $\mathrm{FPM}_{1} 1, \mathrm{SDH}_{\mathrm{FPM}} 2$ and Fine and Gray)

\begin{tabular}{|c|c|c|c|c|c|}
\hline Event & Variable & $\mathrm{SDH}_{\mathrm{FPM}} 1$ & $\mathrm{SDH}_{\mathrm{FPM}}{ }^{2}$ & Fine\&Gray Model & $\mathrm{CSH}_{\mathrm{FPM}}$ \\
\hline & & $\mathrm{SD} H R(95 \% \mathrm{Cl})$ & $\mathrm{SD} H R(95 \% \mathrm{Cl})$ & $\mathrm{SD} H R(95 \% \mathrm{Cl})$ & cSHR $(95 \% \mathrm{Cl})$ \\
\hline \multirow[t]{13}{*}{ AIDS } & MACS recruitment & & & & \\
\hline & $1984-85$ \& 1987-90 & Reference & Reference & Reference & Reference \\
\hline & $2001-3 \& 2010$ & $.031(.004-.22)$ & $.035(.005-.25)$ & $.030(.004-.21)$ & $.039(.005-.28)$ \\
\hline & ${ }^{*}$ LR test & $<.0001$ & $<.0001$ & & .001 \\
\hline & Age at diagnosis & & & & \\
\hline & $<40$ & Reference & Reference & Reference & Reference \\
\hline & $\geq 40$ & $.69(.51-.93)$ & $.69(.52-.93)$ & $.70(.51-0.96)$ & $.87(.64-1.18)$ \\
\hline & LR test & .017 & .016 & & .38 \\
\hline & Baseline CD4 & & & & \\
\hline & $<350$ & $1.83(1.16-2.90)$ & $1.70(1.10-2.63)$ & $1.82(1.14-2.90)$ & $1.86(1.19-2.90)$ \\
\hline & $350-500$ & 1.38(.99-1.93) & $1.32(.96-1.83)$ & $1.38(1.00-1.91)$ & $1.33(.96-1.84)$ \\
\hline & $\geq 500$ & Reference & Reference & Reference & Reference \\
\hline & LR test & .016 & .038 & & .016 \\
\hline \multirow[t]{13}{*}{ Non-AIDS } & MACS recruitment & & & & \\
\hline & 1984-85 \& 1987-90 & Reference & Reference & Reference & Reference \\
\hline & $2001-3 \& 2010$ & $3.33(2.04-5.46)$ & $3.57(2.22-5.75)$ & $3.18(1.90-5.35)$ & $2.45(1.51-3.99)$ \\
\hline & LR test & $<.0001$ & $<.0001$ & & .0009 \\
\hline & Age at diagnosis & & & & \\
\hline & $<40$ & Reference & Reference & Reference & Reference \\
\hline & $\geq 40$ & $2.88(1.93-4.31)$ & $3.57(2.21-5.77)$ & $2.51(1.72-3.68)$ & $3.72(2.34-5.90)$ \\
\hline & LR test & $<.0001$ & $<.0001$ & & $<.0001$ \\
\hline & Baseline CD4 & & & & \\
\hline & $<350$ & $1.13(.56-2.32)$ & $.84(.43-1.66)$ & $1.11(.56-2.23)$ & $1.32(.65-2.68)$ \\
\hline & $350-500$ & $.58(.30-1.13)$ & $.58(.30-1.11)$ & $.57(.29-1.12)$ & $.68(.35-1.32)$ \\
\hline & $\geq 500$ & Reference & Reference & Reference & Reference \\
\hline & LR test & .19 & .42 & & .33 \\
\hline \multirow[t]{9}{*}{ Death } & Age at diagnosis & & & & \\
\hline & $<40$ & Reference & Reference & Reference & Reference \\
\hline & $\geq 40$ & $2.95(1.07-8.15)$ & $3.28(1.19-8.99)$ & $2.91(1.05-8.04)$ & $3.71(1.34-10.28)$ \\
\hline & LR test & .037 & .021 & & .012 \\
\hline & Baseline CD4 & & & & \\
\hline & $<350$ & - & - & - & - \\
\hline & $350-500$ & 1.79(.57-5.63) & $1.91(.62-5.91)$ & $1.77(.57-5.54)$ & $2.04(.65-6.41)$ \\
\hline & $\geq 500$ & Reference & Reference & Reference & Reference \\
\hline & LR test & .17 & .13 & & .18 \\
\hline
\end{tabular}

*LR test is the Likelihood Ratio test for evaluating the effect of each covariate in the multivariable $\mathrm{SDH}_{\mathrm{FPM}} 1, \mathrm{SDH}_{\mathrm{FPM}} 2$, and $\mathrm{CSH}_{\mathrm{FPM}}$

equivalent to the effect of covariates on the risk of the event of interest. However, they contain information about the significance and direction of the effects of covariates on the risk of the event of interest [47]. The results of analyses on the multiply imputed data sets were almost identical to CCA (refer to Appendix).
Associations of MACS recruitments with the risk of AIDS prior to non-AIDS diseases, non-AIDS prior to AIDS and unrelated death

The results showed that the hazard of AIDS occurrence in period 2 declined to about $96 \%$ compared to period $1(P$-value $=.002)$. In addition, the hazard of 
non-AIDS diseases among patients of period 2 was 2.45 times that of period $1(P$-value $=.002)$. By increasing the hazard of non-AIDS diseases in period 2, fewer patients remained at risk to experience AIDS prior to non-AIDS diseases compared to period 1 . Consequently, the risk of observing AIDS as the first event was lower in period 2 compared to period 1 ( $P$ value $=.0001)$. In a similar way, the risk of observing a non-AIDS disease prior to AIDS increased in period 2 compared to period 1 (P-value <.0001). Therefore, there were direct and indirect associations between the MACS recruitments and the risk of AIDS and non-AIDS. MACS recruitments were not associated with the hazard and risk of unrelated death.

Associations of age at HIV diagnosis with the risk of AIDS prior to non-AIDS diseases, non-AIDS prior to AIDS and unrelated death

Age at HIV diagnosis was not associated with the hazard of AIDS $(P$-value $=.38)$. However, the risk of AIDS prior to a non-AIDS disease in the $\geq 40$ age group decreased by $31 \%$ compared to 40 ( $\mathrm{P}$-value $=.017$ ). This discrepancy between the hazard and risk of AIDS indicated an indirect effect of age on the risk of AIDS that came from the higher hazard rate of non-AIDS diseases and unrelated death among the older age group. The effects of age groups on both the hazard and risk of non-AIDS diseases, controlling other covariates, were time dependent and the average effect of the $\geq 40$ group on the hazard of non-AIDS diseases was about 3.7 times that of $<40$ group $(P$-value $<.0001$ The risk of non-AIDS diseases and unrelated death was higher among $\geq 40$ age group (P-value <.0001, .039 respectively). As a result, fewer patients in the $\geq 40$ age group remained exposed to experience AIDS prior to non-AIDS diseases. These findings also indicated that age at diagnosis had direct effects on the risks of non-AIDS and unrelated death.

\section{Associations of CD4 levels with the risk of AIDS prior to non-AIDS diseases, non-AIDS prior to AIDS and unrelated death}

Hazard of AIDS increased about 83\% for CD4 levels < 350 compared to CD4 levels $\geq 500(P$-value $=.018)$. The risk of AIDS for patients with CD4 cells < 350 reached statistical significance comparing to patients with $\geq 500$ $(\mathrm{P}$-value $=.027)$. Levels of CD4 had no significant association with the hazards and risks of non-AIDS diseases. Hence, the effect of CD4 levels on the risk of AIDS was quite direct. Levels of CD4 had no significant associations with hazards and risks of non-AIDS diseases and unrelated death. Hence, the effect of CD4 levels on the risk of AIDS was quite direct.

We compared risk estimations of competing events for different patterns of covariates in a 15 -year time interval using all subdistribution hazard-based models (i.e. $\mathrm{SDH}_{\mathrm{FPM}} 1,2$ and Fine \& Gray). Figs. 1, 2, and 3 show that risk estimations obtained from $\mathrm{SDH}_{\mathrm{FPM}} 1$ and 2 were close to their corresponding values in the Fine \& Gray model. The $\mathrm{SDH}_{\mathrm{FPM}} 1$ and 2 could accurately capture nonlinear trends of the risk of AIDS in different patterns of covariates and provide parametric estimations of them. For all patterns, the risk estimations of AIDS were dramatically higher than non-AIDS and risks of death were close to zero.

Figure 4, 5, and 6 demonstrate the stacked risk of the first event regardless of the type of the event and separated by the type of events. They compare risk estimations obtained from $\mathrm{SDH}_{\mathrm{FPM}} 1$ between different groups of patients. Fig. 4 compares the total risk of failure among two patients from periods 1 and 2 with controlling other covariates at the baseline level (the lowest level). The risk of experiencing the first event for a patient from period 1 was dramatically higher than period 2. In contrast, the risk of failure for a patient from period 2 was mostly related to non-AIDS diseases. Figs. 5 and 6 also show comparisons of stacked risks between two age groups at diagnosis and CD4 levels, respectively. Risk of failure for a patient $<40$ years was almost equivalent to a patient $\geq 40$ years. However, the probability that the failure is due to AIDS is higher for younger patients. The risk of experiencing a disease, mostly AIDS, for a patient with the lowest level of CD4 was higher than a patient with the highest level of CD4. The probability that a patient fails from death prior to experiencing a disease was near zero in all figures.

\section{Discussion}

We have presented a comparison between competing risks flexible parametric and Fine \& Gray models for the first disease among HIV positive men using the ongoing MACS data set. Two alternative subdistribution flexible parametric models were used. One of them was based on censoring weights and was performed for each competing event separately. The other one was based on direct estimations of the subdistribution functions and was performed simultaneously for all three competing risks. All the three models were similar regarding the estimations of covariate effects, their confidence intervals, and risk estimations. The main disadvantage of the Fine \& Gray models is that the baseline risks remain unspecified and are assessed nonparametrically in a further step. They are, however, very flexible and do not make any assumptions on the shape of baseline functions. As the most important finding in our study, the $\mathrm{SDH}_{\mathrm{FPM}} \mathrm{S}$ provided parametric estimations, which presented the data at hand accurately. They captured the complicated and nonlinear trend of the risk of AIDS using NCSs and provided smooth estimations. Among two subdistribution hazard-based flexible parametric models, $\mathrm{SDH}_{\mathrm{FPM}} 2$ is 
more straightforward to run than $\mathrm{SDH}_{\mathrm{FPM}} 1$ and can be directly implemented on the original data. In addition, calculating censoring weights and splitting the data in $\mathrm{SDH}_{\mathrm{FPM}} 1$ leads to intensive computations, which are time-consuming and require a large computer memory especially for large data sets. Mozumder used SEER colorectal cancer data with more than 45,000 observations and showed that the $\mathrm{SDH}_{\mathrm{FPM}} 2$ runs fundamentally quicker than estimating the censoring weights and splitting the data [41]. Furthermore, $\mathrm{SDH}_{\mathrm{FPM}} 2$ is fitted on all three competing events simultaneously. However, if interest is in only one event there is no need to perform a model for all competing events and $\mathrm{SDH}_{\mathrm{FPM}} 1$ may be preferred [30]. One shortcoming of $\mathrm{SDH}_{\mathrm{FPM}} 2$ is that the model has some convergence problems with small sample sizes. Another problem with this model is that though the model fits for all competing events at the same time, there is no constraint on the sum of all cause-specific CIFs to be less than one [30]. This is also the case for $\mathrm{SDH}_{\mathrm{FPM}} 1$ because the models are fitted for each event separately $[29,30]$.

Using $\mathrm{SDH}_{\mathrm{FPM}} \mathrm{S}$, we investigated which covariates are associated with the risk of the first disease among HIV infected men. However, the effect of a covariate on the risk of an event can be misleading if not properly interpreted. Austin and Fine [47] conducted a review in medical papers, published in 2015, and showed that many of these papers had an incorrect interpretation of the results of the Fine \& Gray model. In our study, the risk of AIDS prior to non-AIDS among patients with $\geq 40$ age at diagnosis was less than $<40$, whereas it has no significant effect on the occurrence of AIDS. This implies that the hazard of developing AIDS for a patient infected with HIV at the age of 60 is not statistically different from a patient infected at the age of 30. In a competing risks framework, in which the occurrence of the first event is raised, the unrelated death or non-AIDS diseases among $\geq 40$ are more likely compared to $<40$ and many elderly patients experience unrelated death or non-AIDS diseases prior to AIDS. So, fewer patients in $\geq 40$ age group remain in the risk set of experiencing AIDS as the first event and the probability of AIDS occurrence as the first disease among them is reduced. As a result, we have implemented cause-specific hazards flexible parametric models in addition to subdistribution hazard flexible parametric models. We agree with the recommendation that both cause-specific hazards and subdistribution hazards-based models should be used for a comprehensive inference in competing risks analyses $[10,11]$. Using $\mathrm{CSH}_{\mathrm{FPM}}$ as well as $\mathrm{SDH}_{\mathrm{FPM}}$, we could investigate the consistency of the effects of covariates on the hazards and risks of competing events and direct and indirect effects of them on the risks. The $\mathrm{CSH}_{\mathrm{FPM}}$ can be performed for each event separately or as a unified model on the stacked data. The advantage of the unified model

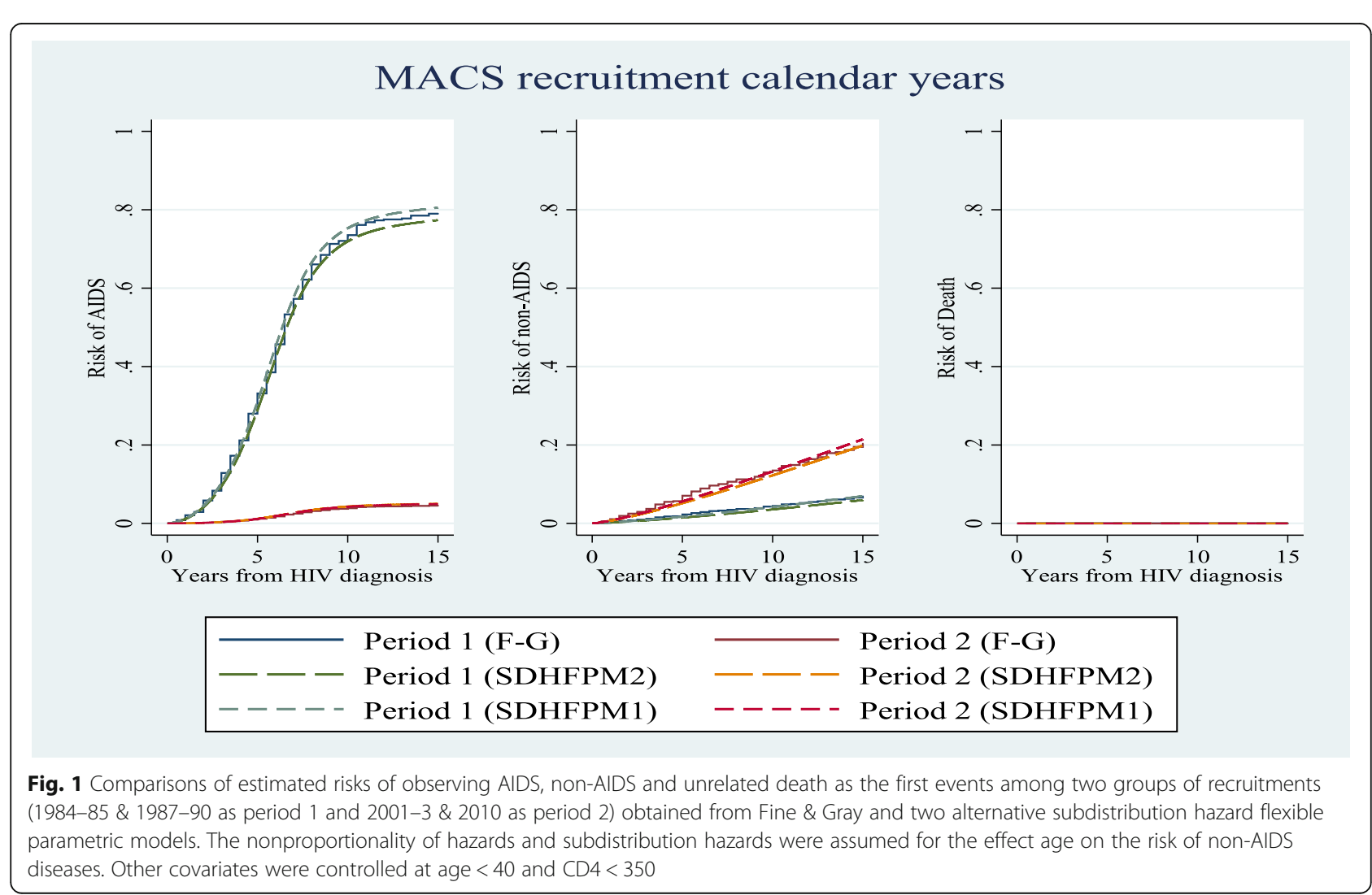




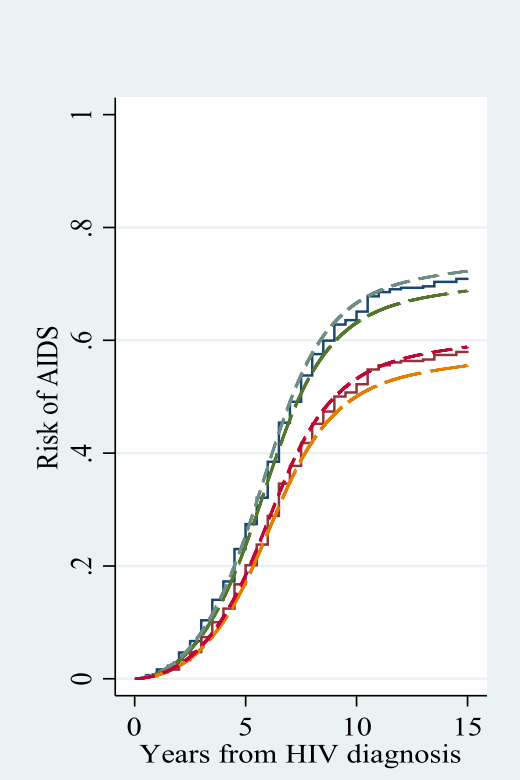

\section{Age at HIV diagnosis}
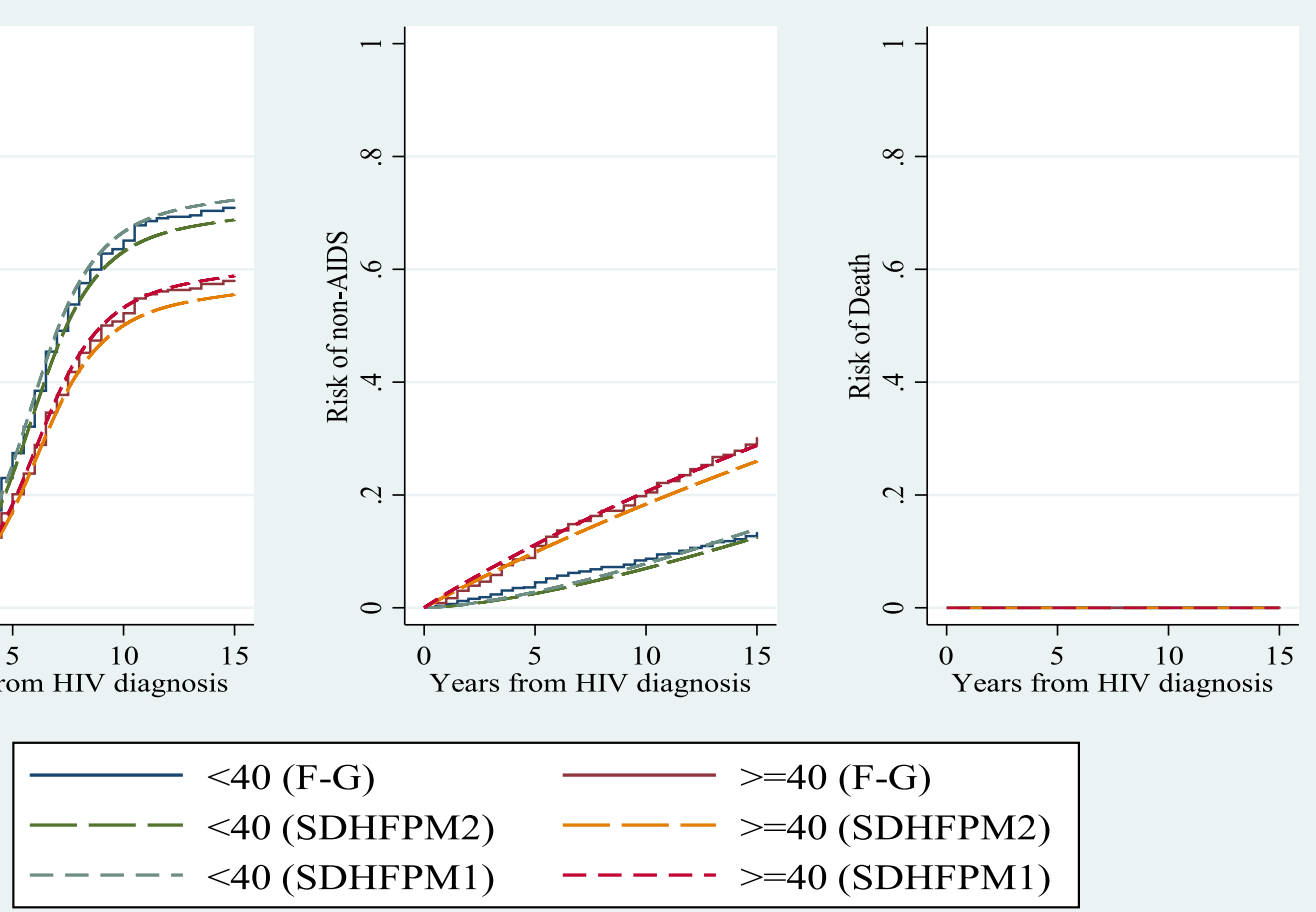

Fig. 2 Comparisons of estimated risks of AIDS, non-AIDS and unrelated death as the first events among $<40$ and $\geq 40$ age groups of seroconversion obtained from Fine \& Gray and two alternative subdistribution hazard flexible parametric models. The nonproportionality of hazards and subdistribution hazards were assumed for the effect of age on non-AIDS diseases. Other covariates were controlled at period 1 (1984-85 \& 1987-90) of MACS recruitments and CD4 < 350

over separate $\mathrm{CSH}_{\mathrm{FPM}} \mathrm{S}$ is that there is no need to implement FPMs on each event separately. However, using a unified $\mathrm{CSH}_{\mathrm{FPM}}$ has some drawbacks. The unified model, by default, considers the same knot positions for all events. Also, the model is more complicated than separate $\mathrm{CSH}_{\mathrm{FPM}}$ and convergence problems may occur.

Another important aspect of this study was investigating the occurrence of different types of events among HIV positive patients at the presence of each other. Recently, Pettit et.al [48]. showed that the risk of non-AIDS mortality among patients with an AIDS-defining event was twice higher than patients without an AIDS-defining event. However, most of the HIV studies were focused on AIDS and non-AIDS separately. Baker et.al [6]. examined the association of baseline CD4 cell counts on the AIDS and non-AIDS separately. They showed that the higher CD4 levels at baseline were associated with a lower risk of nonAIDS diseases $(\mathrm{HR}=.84,95 \%$ CI (.74-.96)). However, considering an AIDS-prior event as a confounder, there was no significant association between baseline CD4 and non-AIDS diseases. This is consistent with our findings, which indicated that the risk of the occurrence of non-
AIDS prior to AIDS is not associated with baseline CD4 levels at the presence of AIDS.

One of the limitations of this study was the challenge of Events-Per-Variable (EPV) for deaths prior to AIDS or non-AIDS disease, which may lead to sparse data biases and overfitting problem [49]. However, the main focus of this study was on AIDS and non-AIDS events. So, unrelated death was considered as a competing event that precludes the occurrence of AIDS/non-AIDS diseases. Another limitation was the lack of goodness of fit tests that be able to compare $\mathrm{SDH}_{\mathrm{FPM}} 1$ with $\mathrm{SDH}_{\mathrm{FPM}} 2$. $\mathrm{SDH}_{\mathrm{FPM}} \mathrm{S}$ are newly developed approaches and probably the next step would be developing goodness of fit criteria for comparing them.

\section{Conclusion}

This paper presents an application of flexible parametric models on multiple event types when each event alters the probability of occurrence of the other events. The choice of an appropriate model depends on the goals of the research and computational challenges. A review of these models and their required packages are summarized in Table 3. 


\section{levels of CD4}
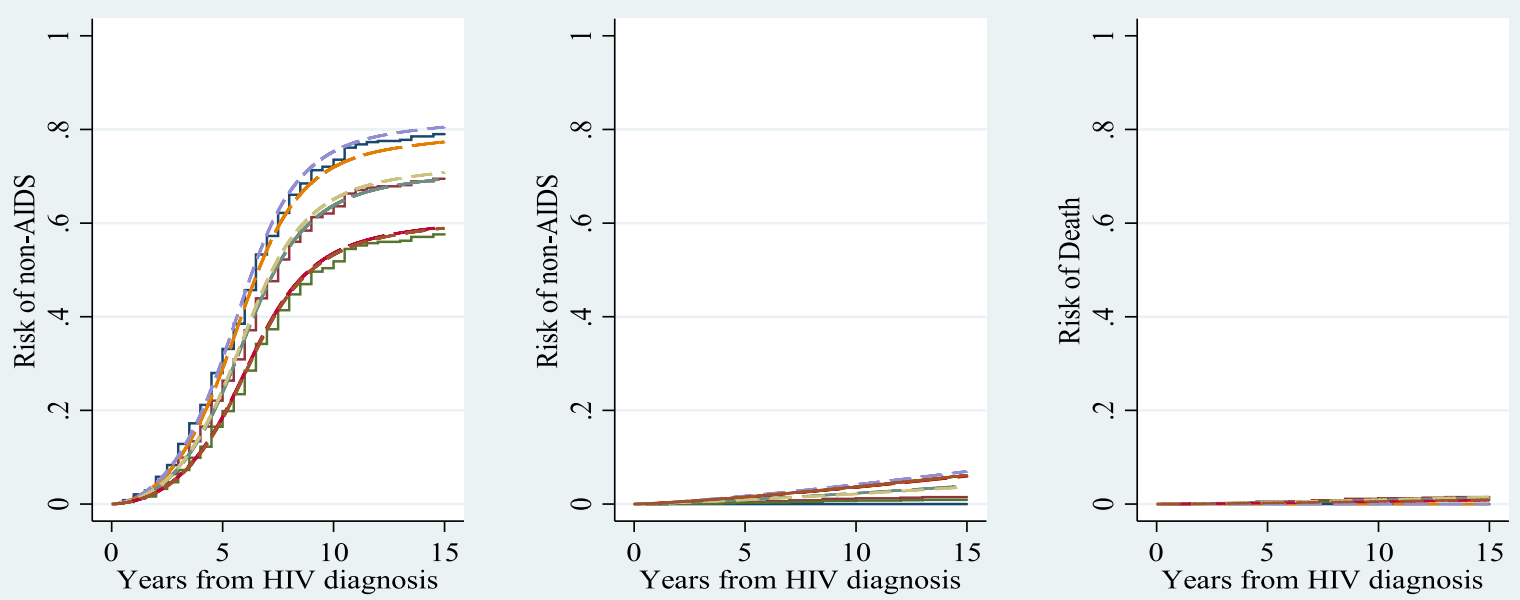

$$
\begin{array}{|lll|}
- & -350(\mathrm{~F}-\mathrm{G}) & -350-500(\mathrm{~F}-\mathrm{G}) \\
->=500(\mathrm{~F}-\mathrm{G}) & ---<350(\text { SDHFPM2) } \\
--- & 350-500 \text { (SDHFPM2) } & --->=500 \text { (SDHFPM2) } \\
-----<350 \text { (SDHFPM1) } & -----350-500 \text { (SDHFPM1) } \\
----->=500 \text { (SDHFPM1) } &
\end{array}
$$

Fig. 3 Comparisons of estimated risks of AIDS, non-AIDS and unrelated death as the first events among three levels of CD4 obtained from Fine \& Gray and two alternative subdistribution hazard flexible parametric models. The nonproportionality of hazards and subdistribution hazards were assumed for the effect of age on non-AIDS diseases. Other covariates were controlled at period 1 (1984-85 \& 1987-90) of MACS recruitments and age $<40$
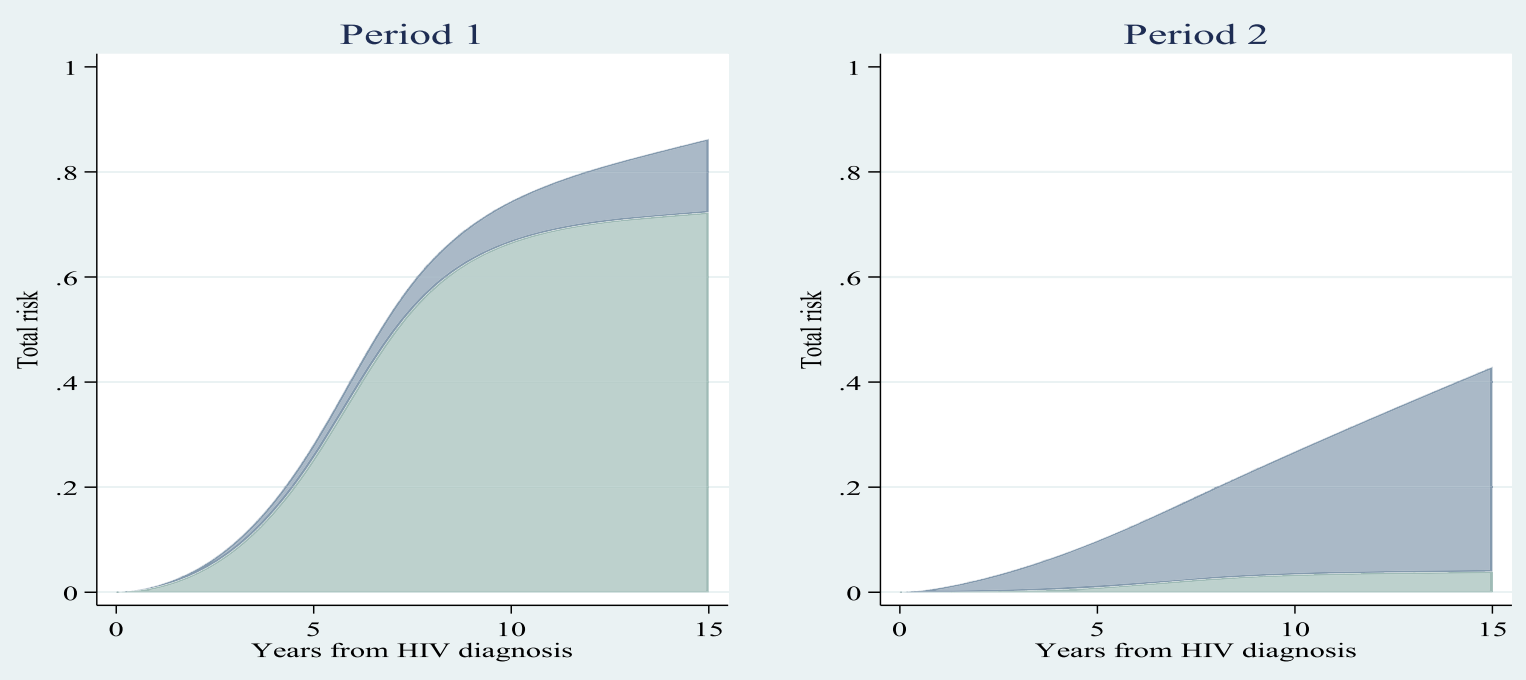

Failing with AIDS

Failing with Non-AIDS

Death

Fig. 4 A comparison of stacked risks among MACS recruitments (1984-85 \& 1987-90 as period 1 and 2001-3 \& 2010 as period 2) for patients with age $<40$ and $C D 4<350$ 

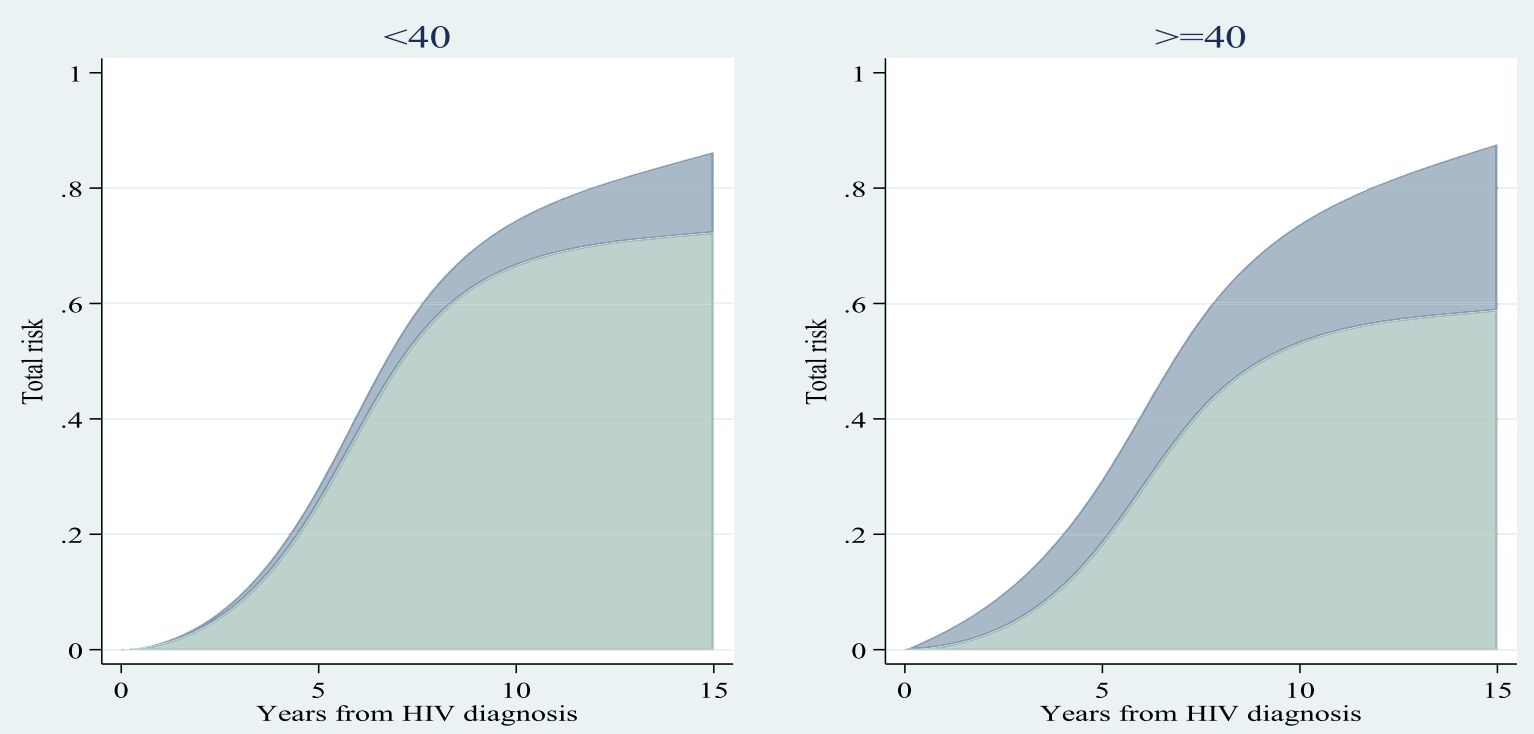

Failing with AIDS

Failing with Non-AIDS

Death

Fig. 5 A comparison of stacked risks between two groups of age at diagnosis for patients in period 1 (1984-85 \& 1987-90) of MACS recruitments with $\mathrm{CD} 4<350$
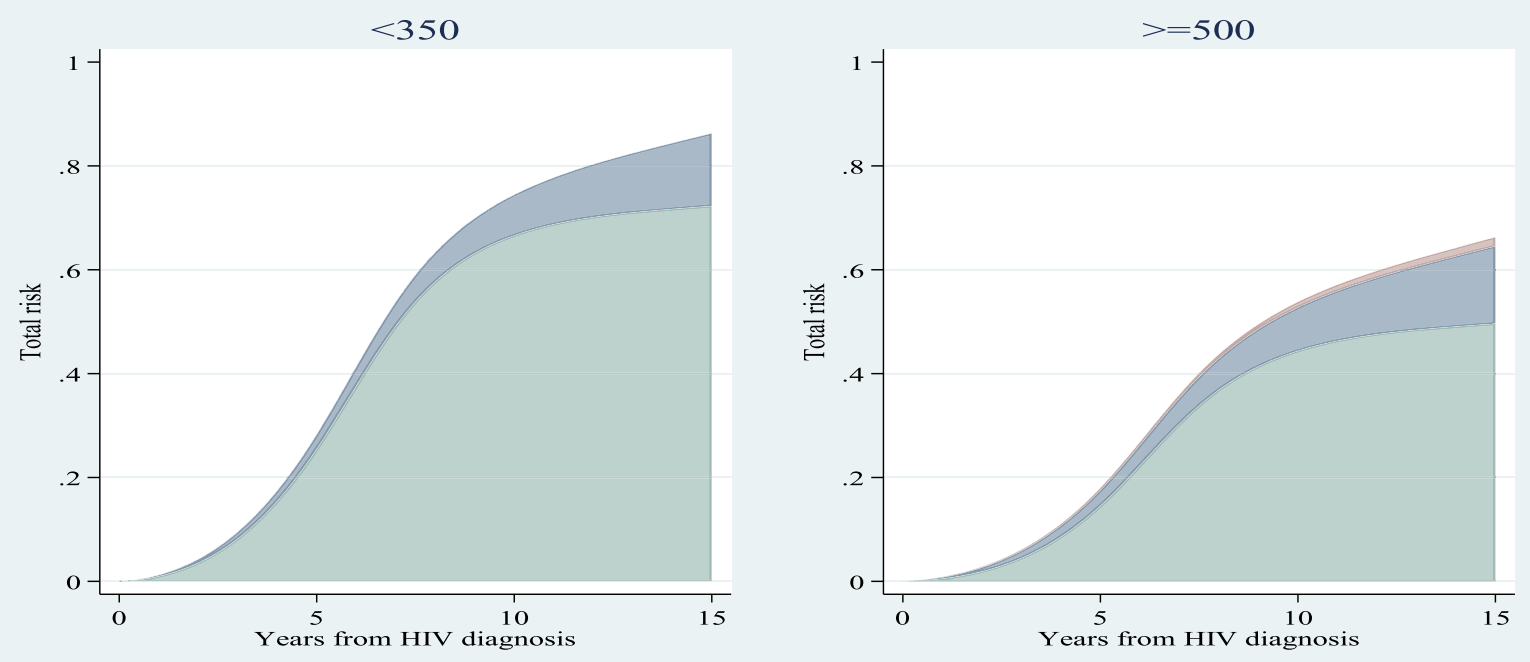

Failing with AIDS

Failing with Non-AIDS

Death

Fig. 6 A comparison of stacked risks between two levels of baseline CD4 for patients in Period 1 (1984-85 \& 1987-90) of MACS recruitments with age $<40$ 
Table 3 Approaches of Competing Risks Flexible Parametric Models

\begin{tabular}{|c|c|c|c|c|c|c|}
\hline Model & $\begin{array}{l}\text { Measures of } \\
\text { associations }\end{array}$ & $\begin{array}{l}\text { What is the model } \\
\text { useful for? }\end{array}$ & $\begin{array}{l}\text { How to } \\
\text { model? }\end{array}$ & Advantages & Disadvantages & $\begin{array}{l}\text { Which Stata } \\
\text { commands? }\end{array}$ \\
\hline \multirow[t]{2}{*}{$\begin{array}{l}\text { Cause-specific } \\
\text { hazard flexible } \\
\text { parametric } \\
\text { model }\end{array}$} & hazard & $\begin{array}{l}\text { Etiological questions: } \\
\text { which covariates have } \\
\text { a causal effect on the } \\
\text { occurrence of the } \\
\text { event }\end{array}$ & $\mathrm{CSH}_{\mathrm{FPM}}$ & $\begin{array}{l}\text { Easy to perform (on the original } \\
\text { data) and interpret, using the } \\
\text { standard FPM }\end{array}$ & $\begin{array}{l}\text { Fitting separate models for } \\
\text { each event }\end{array}$ & stpm2 \\
\hline & & & $\begin{array}{l}\text { Unified } \\
\mathrm{CSH}_{\mathrm{FPM}}\end{array}$ & $\begin{array}{l}\text { Fitting one model instead of } \\
\text { separate models, using the } \\
\text { standard FPM, Ability to handle } \\
\text { shared covariate effects }\end{array}$ & $\begin{array}{l}\text { Considering the same knot } \\
\text { positions for all events, } \\
\text { complex implementation (on } \\
\text { the stacked data), Potential } \\
\text { convergence problems }\end{array}$ & $\begin{array}{l}\text { Stratified } \\
\text { stpm2 }\end{array}$ \\
\hline \multirow[t]{2}{*}{$\begin{array}{l}\text { Cause-specific } \\
\text { subdistribution } \\
\text { hazard flexible } \\
\text { parametric } \\
\text { model }\end{array}$} & $\begin{array}{l}\text { Subdistribution } \\
\text { hazard and } \\
\text { cumulative } \\
\text { incidence } \\
\text { function (risk) }\end{array}$ & $\begin{array}{l}\text { Prognosis questions: } \\
\text { What fraction of } \\
\text { patients are at risk to } \\
\text { experience the event } \\
\text { at a particular time }\end{array}$ & $\mathrm{SDH}_{\mathrm{FPM}} 1$ & $\begin{array}{l}\text { Fitting a separate model for the } \\
\text { event of interest, using the } \\
\text { standard FPM }\end{array}$ & $\begin{array}{l}\text { Intensive computation (not } \\
\text { ideal for large data sets), no } \\
\text { constraint on the sum of CIFs }\end{array}$ & $\begin{array}{l}\text { stcrprep } \\
\text { and stpm2 }\end{array}$ \\
\hline & & & $\mathrm{SDH}_{\mathrm{FPM}}{ }^{2}$ & $\begin{array}{l}\text { Fitting a unified model for all } \\
\text { events (when the focus is on all } \\
\text { events), Easy to perform (on the } \\
\text { original data) and interpret, Less } \\
\text { computation (ideal for large data } \\
\text { sets) }\end{array}$ & $\begin{array}{l}\text { convergence problems for } \\
\text { small sample sizes, no } \\
\text { constraint on the sum of CIFs }\end{array}$ & stpm $2 \mathrm{cr}$ \\
\hline
\end{tabular}

\section{Appendix \\ sensitivity analysis}

The data contained covariate missing values $(7.6 \%$ of individuals had at least one missing value in their covariates). To address the impact of missing data, we used MI to examine whether the associations estimated in the standard analyses (Fine \& Gray models) could have been biased due to exclusion of patients with missing data (CCA). Age at diagnosis, CD4, CD8, WBC, RBC, and platelets were registered for imputation. Survival outcomes consist of survival time and type of the event (as a factor with 4 categories for AIDS, non-AIDS, death and censoring), and MACS recruitment years were considered as predictors of the imputation models. In addition, we used hemoglobin as axillary information. For imputation, the multivariate normal regression method was used and $n=10$ imputed data set were created. Univariate analyses on multiply imputed data sets were fairly close to CCA. Additional file 2: Table S2. includes the pooled results of final Fine \& Gray models on the imputed data. The results are almost identical to CCA.

\section{Supplementary information}

Supplementary information accompanies this paper at https://doi.org/10. 1186/s12874-020-0900-Z

Additional file 1: Table S1. Results of Transforming and Imputing Variables.

Additional file 2: Table S2. Results from the Fine \& Gray Analysis of 10 Multiply Imputed Datasets.

\section{Abbreviations}

AIC: Akaike Information Criterion; AIDS: Acquired Immunodeficiency Syndrome; CCA: Complete Case Analysis; CIF: Cumulative Incidence Function; $C_{\text {FPM: }}$ : Competing Risks Flexible Parametric Model; $\mathrm{CSH}_{\mathrm{FPM}}$ : Cause-Specific Hazard Flexible Parametric Model; EPV: Events-Per-Variable; FPM: Flexible Parametric Model; HBM: Homosexual and Bisexual Men; HIV: Human Immunodeficiency Virus; LR: Likelihood Ratio; MACS: Multicenter AIDS Cohort Study; MCAR: Missing Completely at Random; MI: Multiple Imputations; $\mathrm{SDH}_{\mathrm{FPM}}$ : Subdistribution Hazard Flexible Parametric Model

\section{Acknowledgments}

This paper was a part of research towards a Ph.D. degree in Biostatistics at the School of Public Health, Tehran University of Medical Sciences (TUMS). Most of this research was conducted while the first author was a visiting student at the faculty of Health Sciences (School of Nursing), McMaster University in Hamilton, Canada. Data in this manuscript were collected by the Multicenter AIDS Cohort Study (MACS). MACS (Principal Investigators): Johns Hopkins University Bloomberg School of Public Health (Joseph Margolick, Todd Brown), U01-Al35042; Northwestern University (Steven Wolinsky), U01-Al35039; University of California, Los Angeles (Roger Detels, Otoniel Martinez-Maza, Otto Yang), U01-Al35040; University of Pittsburgh (Charles Rinaldo, Lawrence Kingsley, Jeremy Martinson), U01-Al35041; the Center for Analysis and Management of MACS, Johns Hopkins University Bloomberg School of Public Health (Lisa Jacobson, Gypsyamber D'Souza), UM1-Al35043. The MACS is funded primarily by the National Institute of Allergy and Infectious Diseases (NIAID), with additional co-funding from the National Cancer Institute (NCl), the National Institute on Drug Abuse (NIDA), and the National Institute of Mental Health (NIMH). Targeted supplemental funding for specific projects was also provided by the National Heart, Lung, and Blood Institute (NHLBI), and the National Institute on Deafness and Communication Disorders (NIDCD). MACS data collection is also supported by UL1-TR001079 (JHU ICTR) from the National Center for Advancing Translational Sciences (NCATS) a component of the National Institutes of Health $(\mathrm{NIH})$, and NIH Roadmap for Medical Research. The contents of this publication are solely the responsibility of the authors and do not represent the official views of the National Institutes of Health (NIH), Johns Hopkins ICTR, or NCATS. The MACS website is located at http://aidscohortstudy.org/.

\section{Authors' contributions}

SN and NA determined the overall scope of this study. SN planned the analytical strategies, analyzed the data, interpreted the results, drafted and 
revised the manuscript. NA provided feedback on the data analysis and earlier drafts of the manuscript. MaM supervised the whole work. MoM offered feedback on the manuscript and contributed to the revision of the manuscript. All authors read and approved the final manuscript.

\section{Funding}

This research received no specific grant from any funding agency in the public, commercial, or not-for-profit sectors.

\section{Availability of data and materials}

The datasets generated and/or analyzed during the current study are available in the Multicenter AIDS Cohort Study (MACS) repository, [http:// aidscohortstudy.org/researchers/].

\section{Ethics approval and consent to participate}

Not applicable.

\section{Consent for publication}

Not applicable.

\section{Competing interests}

The authors declare that they have no competing interests.

\section{Author details}

${ }^{1}$ Department of Epidemiology and Biostatistics, School of public health Tehran University of Medical Sciences, Tehran, Iran. ${ }^{2}$ School of Nursing, Faculty of Health Sciences, McMaster University, Hamilton, Canada. ${ }^{3}$ Department of Health Research Methods, Evidence, and Impact, McMaster University, Hamilton, Canada.

Received: 16 July 2019 Accepted: 7 January 2020

Published online: 29 January 2020

\section{References}

1. Patel P, Rose CE, Collins PY, Nuche-Berenguer B, Sahasrabuddhe W, Peprah E, et al. Noncommunicable diseases among HIV-infected persons in lowincome and middle-income countries: a systematic review and metaanalysis. AIDS. 2018;32(Suppl 1):S5-20.

2. Masia M, Padilla S, Moreno S, Barber X, Iribarren JA, Del Romero J, et al. Prediction of long-term outcomes of HIV-infected patients developing nonAIDS events using a multistate approach. PLoS One. 2017;12(9):e0184329.

3. Serrano-Villar S, Perez-Elias MJ, Dronda F, Casado JL, Moreno A, Royuela A, et al. Increased risk of serious non-AIDS-related events in HIV-infected subjects on antiretroviral therapy associated with a low CD4/CD8 ratio. PLoS One. 2014;9(1):e85798.

4. Wolbers M, Koller MT, Stel VS, Schaer B, Jager KJ, Heinze G, et al. Statistical tutorials Competing risks analyses : objectives and approaches. Eur Heart J. 2014;35(42):2936-41.

5. van Stralen KJ, Jager K, Noordzij M, Leffondré K, Zoccali C, Dekker FW. When do we need competing risks methods for survival analysis in nephrology? Nephrol Dial Transplant [Internet]. 2013;28(11):2670-7 Available from: https://doi.org/10.1093/ndt/gft355.

6. Baker JV, Peng G, Rapkin J, Abrams DI, Silverberg MJ, MacArthur RD, et al. CD4+ count and risk of non-AIDS diseases following initial treatment for HIV infection. AIDS. 2008;22(7):841-8.

7. Serrano-villar S, Pe A, Sainz T, Navas E, Hermida M, Royuela A, et al. Increased Risk of Serious Non-AIDS-Related Events in HIV-Infected Subjects on Antiretroviral Therapy Associated with a Low CD4 / CD8 Ratio. 2014;9(1): e85798

8. Bruchfeld J, Correia-Neves M, Källenius G. Tuberculosis and HIV Coinfection. Cold Spring Harb Perspect Med. 2015;5(7):a017871.

9. Putter H, Fiocco M, Geskus RB. Tutorial in biostatistics: competing risks and multi-state models. Stat Med. 2007 May;26(11):2389-430.

10. Lau B, Cole SR, Gange SJ. Competing risk regression models for epidemiologic data. Am J Epidemiol. 2009;170(2):244-56.

11. Wolbers M, Koller MT, Stel VS, Schaer B, Jager KJ, Leffondré K, et al. Competing risks analyses: objectives and approaches. Eur Heart J. 2014 Nov; 35(42):2936-41.

12. Austin PC, Lee DS, Fine JP. Introduction to the analysis of survival data in the presence of competing risks. Circulation. 2016;133(6):601-9.
13. Donoghoe MW, Gebski V. The importance of censoring in competing risks analysis of the subdistribution hazard. BMC Med Res Methodol. 2017;17(1):52.

14. Andersen PK, Geskus RB, de Witte T, Putter H. Competing risks in epidemiology: possibilities and pitfalls. Int J Epidemiol [Internet]. 2012;41(3): 861-70 Available from: https://doi.org/10.1093/ije/dyr213.

15. Kim HT. Cumulative incidence in competing risks data and competing risks regression analysis. Clin Cancer Res. 2007 Jan;13(2 Pt 1):559-65.

16. Zhang $\mathrm{M}-J$, Zhang $\mathrm{X}$, Scheike TH. Modeling cumulative incidence function for competing risks data. Expert Rev Clin Pharmacol. 2008;1(3):391-400.

17. Scheike TH, Zhang M-J, Gerds TA. Predicting cumulative incidence probability by direct binomial regression. Biometrika [internet]. 2008;95(1): 205-20 Available from: https://doi.org/10.1093/biomet/asm096.

18. Wolbers M, Blanche P, Koller MT, Witteman JCM, Gerds TA. Concordance for prognostic models with competing risks. Biostatistics. 2014;15(3):526-39.

19. Prentice RL, Kalbfleisch JD, Peterson AVJ, Flournoy N, Farewell VT, Breslow NE. The analysis of failure times in the presence of competing risks. Biometrics. 1978:34(4):541-54.

20. Fine JP, Gray RJ. A proportional hazards model for the subdistribution of a competing risk. J Am Stat Assoc [Internet]. 1999;94(446):496-509 Available from: https://amstat.tandfonline.com/doi/abs/10.1080/01621459.1999.104 74144.

21. Lau B, Cole SR, Gange SJ. Parametric mixture models to evaluate and summarize hazard ratios in the presence of competing risks with timedependent hazards and delayed entry. Stat Med. 2011;30(6):654-65.

22. Lau B, Cole SR, Moore RD, Gange SJ. Evaluating competing adverse and beneficial outcomes using a mixture model. Stat Med. 2008;27(21):4313-27.

23. Larson MGDG. A mixture model for the regression analysis of competing risks data. J R Stat Soc Ser C. 1985;34:201-11.

24. Escarela G, Bowater RJ. Fitting a semi-parametric mixture model for competing risks in survival data. Commun stat - Theory methods [internet]. 2008;37(2):277-93 Available from: https://doi.org/10.1080/ 03610920701649134

25. Nicolaie MA, van Houwelingen $\mathrm{HCPH}$. Vertical modeling: a pattern mixture approach for competing risks modeling. Stat Med. 2010;29:1190-205.

26. Haller B, Schmidt G, Ulm K. Applying competing risks regression models: an overview. Lifetime Data Anal. 2013;19(1):33-58.

27. Zhang Z. Parametric regression model for survival data: Weibull regression model as an example. Ann Transl Med. 2016;Vol. 4:484.

28. Hinchliffe SR, Lambert PC. Flexible parametric modelling of cause-specific hazards to estimate cumulative incidence functions. BMC Med Res Methodol [Internet]. 2013;13(1):13 Available from: https://doi.org/10.1186/ 1471-2288-13-13.

29. Lambert PC, Wilkes SR, Crowther MJ. Flexible parametric modelling of the causespecific cumulative incidence function. Stat Med [Internet]. 2017;36(9):1429-46 Available from: https:/onlinelibrary.wiley.com/doi/abs/10.1002/sim.7208.

30. Mozumder SI, Rutherford M, Lambert P. Direct likelihood inference on the cause-specific cumulative incidence function: a flexible parametric regression modelling approach. Stat Med. 2018;37(1):82-97.

31. Royston P, Parmar MKB. Flexible parametric proportional-hazards and proportional-odds models for censored survival data, with application to prognostic modelling and estimation of treatment effects. Stat Med. 2002 21(15):2175-97.

32. Lambert PC, Royston P. Further development of flexible parametric models for survival analysis. Stata J [internet]. 2009;9(2):265-90 Available from: https://doi.org/10.1177/1536867X0900900206

33. Hernan MA, Brumback B, Robins JM. Marginal structural models to estimate the causal effect of zidovudine on the survival of HIV-positive men. Epidemiology. 2000;11(5):561-70.

34. Graham NM, Zeger SL, Kuo V, Jacobson LP, Vermund SH, Phair JP, et al. Zidovudine use in AIDS-free HIV-1-seropositive homosexual men in the multicenter AIDS cohort study (MACS), 1987-1989. J Acquir Immune Defic Syndr. 1991;4(3):267-76

35. Hessol NA, Kalinowski A, Benning L, Mullen J, Young M, Palella F, et al. Mortality among participants in the multicenter AIDS cohort study and the Women's interagency HIV study. Clin infect dis [internet]. 2007;44(2):287-94 Available from: https://doi.org/10.1086/510488

36. Cole SR, Hernán MA, Robins JM, Anastos K, Chmiel J, Detels R, et al. Effect of highly active antiretroviral therapy on time to acquired immunodeficiency syndrome or death using marginal structural models. Am J Epidemiol [internet]. 2003;158(7):687-694. Available from: https://doi.org/10.1093/aje/ kwg206. 
37. Graham NMH, Zeger SL, Park LP, Vermund SH, Detels R, Rinaldo CR, et al. The effects on survival of early treatment of human immunodeficiency virus infection. N Engl J med [internet]. 1992;326(16):1037-42 Available from: https://doi.org/10.1056/NEJM199204163261601.

38. Hernán MA, Brumback B, Robins JM. Marginal structural models to estimate the joint causal effect of nonrandomized treatments. J am stat Assoc [internet]. 2001;96(454):440-8 Available from: https://doi.org/10.1198/ 016214501753168154.

39. Lunn M, McNeil D. Applying cox regression to competing risks. Biometrics. 1995 Jun;51(2):524-32.

40. Hinchliffe SR. Advancing and appraising competing risks methodology for better communication of survival statistics. [Internet] [Doctoral dissertation]. University of Leicester; 2013. Available from: http://hdl.handle.net/2381/28176

41. Mozumder SI. Development of flexible parametric models for competing risks and tools to facilitate in the understanding and communication of Cancer survival [internet] [doctoral dissertation]. University of Leicester; 2018. Available from: https://hdl.handle.net/2381/42864

42. Geskus RB. Cause-specific cumulative incidence estimation and the fine and gray model under both left truncation and right censoring. Biometrics. 2011;67(1):39-49.

43. Mozumder SI, Rutherford MJ, Lambert PC. stpm2cr: a flexible parametric competing risks model using a direct likelihood approach for the causespecific cumulative incidence function. Stata J. 2017;17(2):462-89.

44. Harrell FE. Regression modeling strategies. With applications to linear models, logistic regression, and survival analysis. 2nd ed. New York, Berlin, Heidelberg: Springer International Publishing; 2015.

45. Heinze G, Wallisch C, Dunkler D. Variable selection - a review and recommendations for the practicing statistician. Biom J. 2018;60(3):431-49.

46. Core Team R. R: a language and environment for statistical computing. In: R Foundation for statistical computing. Vienna: Austria. URL; 2018. https:// www.R-project.org/.

47. Austin PC, Fine JP. Practical recommendations for reporting Fine-Gray model analyses for competing risk data. Stat Med. 2017;36(27):4391-400.

48. Pettit AC, Giganti MJ, Ingle SM, May MT, Shepherd BE, Gill MJ, et al. Increased non-AIDS mortality among persons with AIDS-defining events after antiretroviral therapy initiation. J Int AIDS Soc. 2018;21(1).

49. Greenland S, Mansournia MA, Altman DG. Sparse data bias: a problem hiding in plain sight. BMJ. 2016;352:11981.

\section{Publisher's Note}

Springer Nature remains neutral with regard to jurisdictional claims in published maps and institutional affiliations.

Ready to submit your research? Choose BMC and benefit from:

- fast, convenient online submission

- thorough peer review by experienced researchers in your field

- rapid publication on acceptance

- support for research data, including large and complex data types

- gold Open Access which fosters wider collaboration and increased citations

- maximum visibility for your research: over $100 \mathrm{M}$ website views per year

At $\mathrm{BMC}$, research is always in progress.

Learn more biomedcentral.com/submissions 